\title{
Effectiveness of Psychological Treatments for Depressive Disorders in Primary Care: Systematic Review and Meta-Analysis
}

Klaus Linde, $M D^{1}$

Kirsten Sigterman, $M D^{1}$

Levente Kriston, $\mathrm{PbD}^{2}$

Gerta Rücker, $P b D^{3}$

Susanne Jamil ${ }^{1}$

Karin Meissner, $M D^{1,4}$

Antonius Schneider, $M D^{1}$

'Institute of General Practice, Technische Universität München, Munich, Germany

${ }^{2}$ Department of Medical Psychology, University Medical Center HamburgEppendorf, Hamburg, Germany

${ }^{3}$ Institute of Medical Biometry and Statistics, University Medical Center Freiburg, Freiburg, Germany

${ }^{4}$ Institute of Medical Psychology, LudwigMaximilians-University Munich, Munich, Germany

\section{in MORE ONLINE www.annfammed.org}

\begin{abstract}
PURPOSE We performed a systematic review of the currently available evidence on whether psychological treatments are effective for treating depressed primary care patients in comparison with usual care or placebo, taking the type of therapy and its delivery mode into account.
\end{abstract}

METHODS Randomized controlled trials comparing a psychological treatment with a usual care or a placebo control in adult, depressed, primary care patients were identified by searches in MEDLINE, Embase, Cochrane Central Register of Controlled Trials (CENTRAL), and PsycINFO up to December 2013. At least 2 reviewers extracted information from included studies and assessed the risk of bias. Random effects meta-analyses were performed using posttreatment depression scores as outcome.

RESULTS A total of 30 studies with 5,159 patients met the inclusion criteria. Compared with control, the effect (standardized mean difference) at completion of treatment was $-0.30(95 \% \mathrm{Cl},-0.48$ to -0.13$)$ for face-to-face cognitive behavioral therapy (CBT), $-0.14(-0.40$ to 0.12$)$ for face-to-face problem-solving therapy, $-0.24(-0.47$ to -0.02$)$ for face-to-face interpersonal psychotherapy, $-0.28(-0.44$ to -0.12$)$ for other face-to-face psychological interventions, -0.43 $(-0.62$ to -0.24$)$ for remote therapist-led CBT, $-0.56(-1.57$ to 0.45$)$ for remote therapist-led problem-solving therapy, $-0.40(-0.69$ to -0.11$)$ for guided selfhelp CBT, and $-0.27(-0.44$ to -0.10$)$ for no or minimal contact CBT.

CONCLUSIONS There is evidence that psychological treatments are effective in depressed primary care patients. For CBT approaches, substantial evidence suggests that interventions that are less resource intensive might have effects similar to more intense treatments.

Ann Fam Med 2015;13:56-68. doi: 10.1370/afm.1719.

\section{INTRODUCTION}

$\mathrm{D}$ epressive disorders are highly prevalent in the general population worldwide. ${ }^{1}$ Major depression ranks fourth on the list of disorders with the highest burden of disease and is expected to be on the top of the list in high-income countries by $2030 .{ }^{2}$ There is consensus that psychological interventions have a central role in the treatment of depressive disorders. ${ }^{3,6}$ This consensus is backed up by evidence from more than 200 randomized controlled trials, which have been summarized recently in large systematic reviews and meta-analyses., ${ }^{7,8}$

Most patients with depressive disorders are seen in primary care, however, most randomized controlled trials have been performed in more specialized settings. Compared with patients referred to specialty mental health care, patients with depression in primary care sometimes have symptoms that are less severe ${ }^{9-11}$ and more somatic. ${ }^{12,13}$ Population-wide administration of psychological treatments is difficult because of the limited number of qualified therapists. Consequently, methods of providing psychological treatments that are less resource intensive are of great interest to primary care.
Klaus Linde, MD

Institute of General Practice

Technische Universität München

Orleansstr 47

D-81667 München, Germany

Klaus.Linde@tum.de 
Several reviews have summarized the available evidence for psychological treatments for depressed primary care patients, but no review has included more than 15 randomized trials. ${ }^{14-16}$ Overall, these reviews suggest that psychological treatments are also effective in the primary care setting. There has been limited evidence indicating interventions that are less resource intensive, such as Internet- or computer-based therapies, might be effective, too. Since 2010, when the literature search of the most current of these reviews was conducted, a number of new primary care trials have been published. In this article we present a systematic review of the currently available evidence on whether psychological treatments compared with usual care or placebo are effective for treating depressed primary care patients, taking the type of therapy and its delivery mode into account.

\section{METHODS}

The analyses presented in this article have been performed as part of a larger multitreatment systematic review of randomized controlled trials of psychological and pharmacological treatments for depression in primary care. Details of the methods have been described in our published protocol. ${ }^{17}$ The trials on pharmacological and psychological interventions differed greatly regarding recruitment strategies, patients, control interventions, and outcomes, ${ }^{18}$ so these trials have been analyzed and summarized separately. ${ }^{19}$

\section{Search Strategy and Study Selection}

We searched MEDLINE, Embase, Cochrane Central Register of Controlled Trials (CENTRAL), and PsycINFO (main search June 2011, last update December 2013; see the Supplemental Appendix for the complete MEDLINE search strategy). We searched trial registries for unpublished and ongoing studies. In addition, we screened references from identified trials and published systematic reviews focusing on studies on depression treatments performed in primary care or community settings $\mathrm{s}^{14-16,20,21}$ for additional trials.

We included randomized controlled trials that compared psychological interventions with usual care or placebo in the treatment of adult patients having unipolar depressive disorders. Psychological treatments were defined as interventions that are based on a scientific theoretical background and that use psychological techniques to reduce symptoms and improve general well-being through modifying motivational, emotional, cognitive, behavioral, or interpersonal processes. For inclusion, they needed to have been performed either as a tailored, verbal communication process between a patient (or a group of patients) and a health care professional in direct or remote (eg, telephone) contact or as a less-intense or nonguided intervention using written information material (eg, book or computer program) that the patient worked through more or less independently. Patients had to be recruited through direct referral from a general practitioner or another primary care physician not specialized in mental health care, or by systematic screening of patients in the waiting room or listed in a primary care physician's practice. We excluded trials that recruited patients from community-based centers specializing in mental health care. Trials had to report results on at least 1 of the following outcomes: response to treatment, remission, a score on a depression scale (posttreatment or change from baseline), or study discontinuation.

Four authors (K.L., K.S., S.J., and K.M.) reviewed all trials for screening selection and extraction. In the first screening, 1 reviewer excluded clearly irrelevant records. In the second screening, 2 reviewers independently checked all remaining records (partly after obtaining full texts). The full texts of articles were obtained for all records that were considered potentially relevant or unclear, and they were assessed formally for eligibility by at least 2 reviewers independently. Disagreements were resolved by discussion.

\section{Data Extraction, Assessment of Risk of Bias, and Outcome Measures}

At least 2 reviewers independently extracted information on patients, methods, and results of all included studies by using a pretested form. The Cochrane Collaboration tool was used to assess risk of bias in the included studies. ${ }^{22}$ Generation of the allocation sequence, concealment of allocation, blinding, incomplete outcome data, and selective outcome reporting were rated as having low, unclear, or high risk of bias. For assessing overall risk of bias in a study, we did not include the blinding item because complete blinding of those providing and receiving psychological treatments is rarely feasible. Even if clinical assessors are blinded, they depend strongly on what patients report. Taking this a priori limitation into account, we considered included trials to have a low risk of bias if none of the remaining 4 items were considered at high risk of bias and not more than 1 item was unclear. If 1 or more items were considered at high risk of bias, the overall risk was considered high. In the remaining studies, risk of bias was considered unclear.

Because the included studies reported results on efficacy in a highly diverse and often incomplete manner, we performed an additional extraction round using a standardized preference approach for extracting or imputing outcome data ${ }^{22,23}$ for meta-analysis. This additional extraction was done by 1 reviewer (K.L.), while 
a second (K.S. or K.M.) cross-checked all extracted data against the original publications and recalculated imputations. Even though the prespecified primary efficacy endpoint for our overall multitreatment systematic review was a response defined as at least a $50 \%$ score reduction on a depression scale, ${ }_{1}^{17}$ we chose to report posttreatment scores in more detail in this article to make our review better comparable with the available reviews. ${ }^{8,14,15}$ Whenever possible, we extracted data for the Beck Depression Inventory for effect size calculation (because this instrument was most widely used). If the data were not available, we used other patient-reported depression scores as second preferences. If patientreported outcome data were not measured, we used data from observer-rated scales (Hamilton Rating Scale for Depression as a third preference, Montgomery-

Asberg Depression Rating Scale as a fourth preference, other scales as last options). We also performed analyses on remission (defined as having a symptom score below a fixed threshold). Study discontinuation was used as an indicator of acceptability. If available, we also extracted the number of patients dropping out for adverse events or adverse effects, as well as the number of patients reporting adverse events or adverse effects.

\section{Classification of Treatments}

Because psychological treatments are considered complex interventions ${ }^{24}$ grouping them can be performed along several dimensions and remains controversial. ${ }^{25}$ Our classification system was largely prespecified and followed published models, ${ }^{8}$ but it needed some modification to account for the clinical heterogeneity in the identified primary studies. We grouped interventions according to the following dimensions: (1) theoretical background-cognitive behavioral therapy (CBT) vs problem-solving therapy vs interpersonal therapy vs

\section{Table 1. Characteristics of Included Studies}

\begin{tabular}{|c|c|c|c|c|c|c|}
\hline $\begin{array}{l}\text { First Author } \\
\text { Risk of Bias }\end{array}$ & No. ${ }^{a}$ & Recruitment & $\begin{array}{l}\text { Depression } \\
\text { Diagnosis }\end{array}$ & $\begin{array}{c}\% \text { Female } \\
\text { Mean Age, } \\
\text { y }\end{array}$ & $\begin{array}{c}\text { Group } 1 \\
\text { (No. of Sessions; } \\
\text { Clinician) }\end{array}$ & $\begin{array}{c}\text { Group } 2 \\
\text { (No. of Sessions; } \\
\text { Clinician) }\end{array}$ \\
\hline \multicolumn{7}{|l|}{ Face-to-face CBT } \\
\hline $\begin{array}{l}\text { Laidlaw } 2008 \\
\text { u (luuul) }\end{array}$ & 44 & Referral & Major depression & $\begin{array}{l}72 \\
74\end{array}$ & $\begin{array}{c}\text { CBT } \\
\text { (8; psychologist) }\end{array}$ & Usual care \\
\hline $\begin{array}{l}\text { Scott } 1997 \\
\text { h (uuuhh) }\end{array}$ & 48 & Referral & Major depression & $\begin{array}{l}67 \\
41\end{array}$ & $\begin{array}{c}\text { Brief CT } \\
\text { (6; therapist) }\end{array}$ & Usual care \\
\hline $\begin{array}{l}\text { Serfaty } 2009 \\
\text { I (Illhul) }\end{array}$ & 137 & $\begin{array}{l}\text { Mainly } \\
\text { screening }\end{array}$ & Depression & $\begin{array}{l}79 \\
74\end{array}$ & $\begin{array}{c}\text { CBT } \\
(\leq 12 ; \text { therapist })\end{array}$ & Usual care \\
\hline $\begin{array}{l}\text { Smit } 2006 \\
\text { I (llhll) }\end{array}$ & 116 & Referral & Major depression & $\begin{array}{l}64 \\
43\end{array}$ & $\begin{array}{c}\text { CBT } \\
\text { (10-12; therapist) }\end{array}$ & Usual care \\
\hline $\begin{array}{l}\text { Teasdale } 1984 \\
\text { h (uuhhl) }\end{array}$ & 44 & Screening & Major depression & $\begin{array}{l}94 \\
38\end{array}$ & $\begin{array}{c}\text { CT } \\
(\leq 20 ; \text { psychologist })\end{array}$ & Usual care \\
\hline \multicolumn{7}{|c|}{ Face-to-face problem-solving therapy } \\
\hline $\begin{array}{l}\text { Barrett } 2001 \\
\text { u (luuuu) }\end{array}$ & 161 & Referral & $\begin{array}{l}\text { Dysthymia, minor } \\
\text { depression }\end{array}$ & $\begin{array}{l}64 \\
44\end{array}$ & $\begin{array}{l}\text { Problem solving } \\
\text { (6; psychologist) }\end{array}$ & Placebo \\
\hline $\begin{array}{l}\text { Mynor-Wallis } 1995 \\
\text { h (uuuhl) }\end{array}$ & 60 & Referral & Major depression & $\begin{array}{l}77 \\
37\end{array}$ & $\begin{array}{l}\text { Problem solving } \\
\text { (6; trained physician) }\end{array}$ & Placebo \\
\hline $\begin{array}{l}\text { Oxman } 2008 \\
\text { u (Ilhuu) }\end{array}$ & 141 & Screening & Minor depression & $\begin{array}{l}58 \\
55\end{array}$ & $\begin{array}{l}\text { Problem solving } \\
\text { (6; counselor) }\end{array}$ & Usual care \\
\hline $\begin{array}{l}\text { Williams } 2000 \\
\text { h (llhlh) }\end{array}$ & 278 & $\begin{array}{l}\text { Referral or } \\
\text { screening }\end{array}$ & $\begin{array}{l}\text { Dysthymia or } \\
\text { minor depression }\end{array}$ & $\begin{array}{l}41 \\
71\end{array}$ & $\begin{array}{c}\text { Problem solving } \\
\text { (6; psychologist/counselor) }\end{array}$ & Placebo \\
\hline Face-to-face interp & nal psy & otherapy & & & & \\
\hline $\begin{array}{l}\text { Schulberg } 1996 \\
\text { h (uuuhh) }\end{array}$ & 185 & Screening & Major depression & $\begin{array}{l}83 \\
38\end{array}$ & $\begin{array}{l}\text { Interpersonal PT } \\
\text { (16; psychologist/ } \\
\text { psychiatrist) }\end{array}$ & Usual care \\
\hline $\begin{array}{l}\text { Van Schaik } 2006 \\
\text { u (ulhul) }\end{array}$ & 143 & Screening & Major depression & $\begin{array}{l}69 \\
68\end{array}$ & $\begin{array}{c}\text { Interpersonal PT } \\
\text { (10; psychologist/nurse) }\end{array}$ & Usual care \\
\hline $\begin{array}{l}\text { BDI = Beck Depression } \\
\text { therapy; CES-D = Cente } \\
\text { HRSD = Hamilton Ratir } \\
\text { Scale; nr = not measu } \\
\text { Clinical Interview for D }\end{array}$ & $\begin{array}{l}\text { tory; } \mathrm{BD} \\
\text { Epidemio } \\
\text { le for De } \\
\text { reporte } \\
\text { isorders; }\end{array}$ & $\begin{array}{l}\mathrm{S}=\text { Beck Depression } \\
\text { gic Studies-Depressic } \\
\text { ession; HSCL-D = Ho } \\
\mathrm{PHQ}-9=\text { Patient He } \\
\mathrm{M}=\text { transtheoretical }\end{array}$ & $\begin{array}{l}\text { ventory-Fast Screen; c= } \\
\text { Scale; } C T=\text { cognitive th } \\
\text { ins Symptom Checklist } \\
\text { Questionnaire for Dep } \\
\text { lodel. }\end{array}$ & $\begin{array}{l}\text { ly change from ba } \\
\text { oy; HAD-D = Hos } \\
\text { ression Scale; } i= \\
\text { ion; PT = psychot }\end{array}$ & $\begin{array}{l}\text { line data available; } c a=\text { circa; } C B \\
\text { al Anxiety and Depression Scale su } \\
\text { outed data; MADRS = Montgome } \\
\text { apy; RDC = Research Diagnostic }\end{array}$ & $\begin{array}{l}\text { cognitive behavioral } \\
\text { cale depression; } \\
\text { Asberg Depression Rating } \\
\text { teria; SCID = Structured }\end{array}$ \\
\hline $\begin{array}{l}\text { Note: Risk of bias: } \mathrm{I}=1 \\
\text { indicate the risk of bias }\end{array}$ & $\begin{array}{l}=\text { unclea } \\
\text { follow }\end{array}$ & $\begin{array}{l}=\text { high. } \text { First letter } \\
5 \text { items: sequence }\end{array}$ & $\begin{array}{l}\text { icates the overall risk } \\
\text { eration, concealment, }\end{array}$ & $\begin{array}{l}\text { inding, not takir } \\
\text { ding, attrition, }\end{array}$ & $\begin{array}{l}\text { nding into account; letters in par } \\
\text { lective reporting, respectively. }\end{array}$ & ieses sequentially \\
\hline
\end{tabular}


psychodynamic therapies vs other interventions; (2) intensity of contact with health care professionalintensively therapist-led (with a minimum of 6 sessions) vs guided self-help (with less than 6 sessions) vs no or minimal contact (with less than 90 minutes of contact) interventions; and (3) face-to-face vs remote contact interventions. Although not all dimensions of this classification system are completely independent, and not all possible combinations present realistic alternatives, we considered it both comprehensive and sufficiently sophisticated to describe reasonably differentiated treatment options that may be present in everyday care and may be relevant to health policy decision making concerning primary care patients with depression.

\section{Meta-Analyses}

Meta-analyses were performed using the Cochrane Informatics and Management Department RevMan 5.2

\begin{tabular}{lcc} 
& Week Posttreatment & \\
Further & Measurement & Response \\
Groups & Score and Instrument & Remission \\
\hline
\end{tabular}

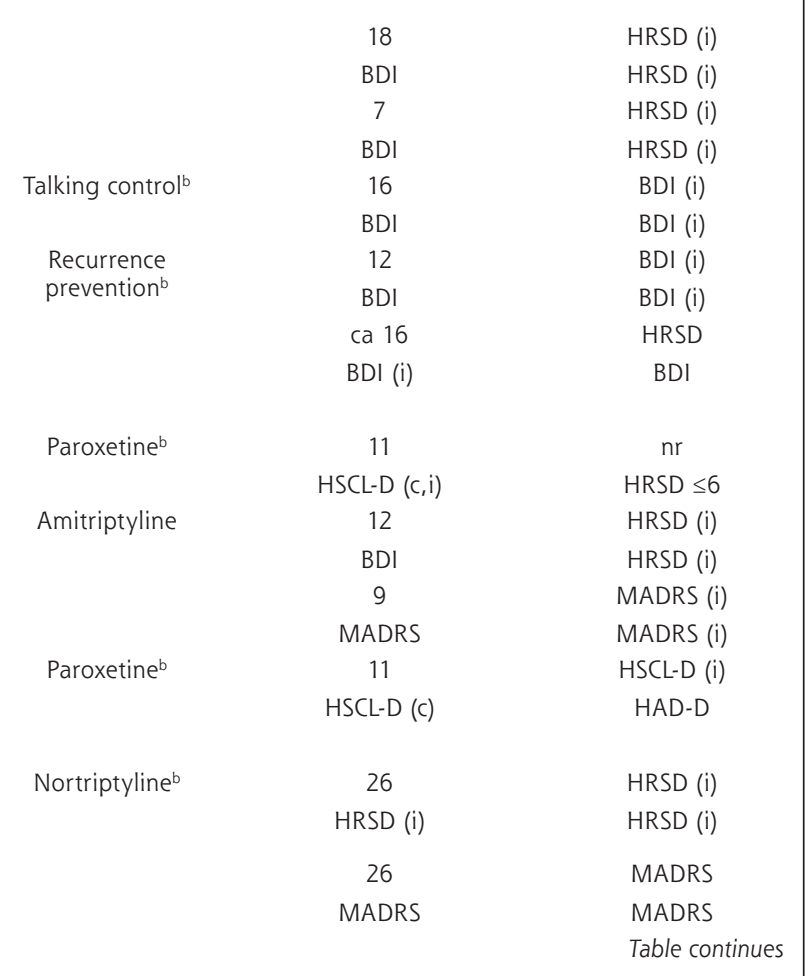

a Number of patients randomized (only in groups included in analyses).

${ }^{b}$ Comparator or control group not included in analyses.

c Trial included 2 separate groups (computerized CBT alone and in combination with usual care), which were pooled.

d Person providing the treatment was explicitly or probably a routine member of the primary care team. software. For posttreatment depression scores, we calculated standardized mean differences (SMD) by subtracting the mean score in the control group from the mean score in the psychological treatment group and dividing the results by the pooled standard deviation. Negative SMDs indicate a better outcome in the psychological treatment group. Odds ratios were calculated for the dichotomous outcomes of response, remission, and study discontinuation. Odds ratios greater than 1 indicate more events in the psychological treatment group compared with the control group. Pooled estimates for all outcomes were calculated using inverse variance weights and random effects models. Statistical heterogeneity of study findings were investigated using $\tau^{2}$, the $\chi^{2}$ test, and the $\mathrm{I}^{2}$ statistic. In the primary analyses, we calculated pooled-effect estimates for each treatment group resulting from our classification system. If we found no substantial statistical heterogeneity between subgroups, results for distinct treatment groups were pooled to calculate an overall effect estimate. Additional subgroup analyses were performed according to clinical diagnosis, delivery mode, treatment concept, recruitment method, number of treatment sessions, risk of bias, and sample size. For easier clinical interpretation, we calculated for the outcomes response and remission the number need to treat (using the total number of patients with response or remission in all included studies divided by the total number of patients with randomized to control groups). To explore any possible small study or publication bias, we produced funnel plots. Tests for funnel plot asymmetry were planned for treatment groups with at least 10 trials.

\section{RESULTS}

\section{Study Selection, Characteristics of Included Studies, and Risk of Bias}

A total of 30 studies (reported in 37 publications) met the inclusion criteria (Table 1; see Supplemental Appendix for a flowchart providing details about the selection process and the full reference lists of included trials). Thirteen trials recruited patients who were referred from the primary care physician, 14 used a screening procedure, and 3 used mixed approaches. Ten trials exclusively included patients meeting diagnostic criteria for major depression; and in 14 trials depression was either not formally diagnosed according to standardized schemes, or patients with a variety of depressive disorders were included. Six trials included only patients with minor depression, dysthymia, or either minor depression or dysthymia. Inclusion criteria were liberal in most trials, making it likely that study participants represent primary care patients with the respective depressive disorders fairly well. The 30 trials 
Table 1. Characteristics of Included Studies (continued)

\begin{tabular}{|c|c|c|c|c|}
\hline $\begin{array}{l}\text { First Author } \\
\text { Risk of Bias }\end{array}$ & No. ${ }^{a}$ & Recruitment & $\begin{array}{l}\text { Depression } \\
\text { Diagnosis }\end{array}$ & $\begin{array}{c}\% \text { Female } \\
\text { Mean Age, } \\
\text { y }\end{array}$ \\
\hline \multicolumn{5}{|c|}{ Other face-to-face psychosocial therapies } \\
\hline \multirow{2}{*}{$\begin{array}{l}\text { Casanas } 2012 \\
\text { I (llhul) }\end{array}$} & \multirow[t]{2}{*}{231} & \multirow[t]{2}{*}{ Referral } & \multirow[t]{2}{*}{ Major depression } & 89 \\
\hline & & & & 53 \\
\hline \multirow{2}{*}{$\begin{array}{c}\text { Corney } 1984 \\
\text { h (huhuh) }\end{array}$} & \multirow[t]{2}{*}{87} & \multirow[t]{2}{*}{ Referral } & \multirow[t]{2}{*}{ Depression } & 100 \\
\hline & & & & 30 \\
\hline \multirow{2}{*}{$\begin{array}{l}\text { Corney } 2005 \\
\text { I (luhll) }\end{array}$} & \multirow[t]{2}{*}{181} & \multirow[t]{2}{*}{ Screening } & \multirow{2}{*}{$\begin{array}{l}\text { Depression } \\
\text { ( } \geq 6 \mathrm{mo})\end{array}$} & 80 \\
\hline & & & & 43 \\
\hline \multirow{2}{*}{$\begin{array}{l}\text { MacPherson } 2013 \\
\text { I (Ilhul) }\end{array}$} & \multirow[t]{2}{*}{453} & \multirow[t]{2}{*}{ Referral } & \multirow[t]{2}{*}{ Depression } & 73 \\
\hline & & & & 44 \\
\hline
\end{tabular}

Three-armed trials with face-to-face CBT and other face-to-face psychosocial therapies

$\begin{array}{ccccc}\text { Scott 1992 } & 121 & \text { Referral } & \text { Major depression } & 76 \\ \text { u (uuuul) } & & & & 32 \\ \begin{array}{c}\text { Ward 2000 } \\ \text { I (ulhll) }\end{array} & 197 & \text { Referral } & \text { Depression } & 77 \\ \text { Remon }\end{array}$

6
77
37

Group 1
No. of Sessions; Clinician)
Psychoeducation
(12; nursec)
Social work

(Unclear; social worker)

Counseling

(6-12; counselorc)

Counseling
(12; counselors)

CBT

(10; psychologist)

CBT

(6-12; psychologist)

Telephone (BT

(8; trained therapist)

Online CBT

( $\leq 10$; psychologist)

Telephone CBT

(8; psychotherapist)

Depression $\quad 76$

44

Remote therapist-led problem-solving therapy

\begin{tabular}{|c|c|c|c|c|c|c|}
\hline $\begin{array}{r}\text { Lynch } 1997 \\
\text { h (uuhhu) }\end{array}$ & 29 & Screening & Minor depression & $\begin{array}{l}86 \\
48\end{array}$ & $\begin{array}{l}\text { Telephone problem solving } \\
\text { (6; trained student) }\end{array}$ & $\begin{array}{l}\text { Usual care, } \\
\text { no treatment }\end{array}$ \\
\hline $\begin{array}{r}\text { Lynch } 2004 \\
\text { h (uuhhh) }\end{array}$ & 54 & Screening & Mild depression & $\begin{array}{l}83 \\
38\end{array}$ & $\begin{array}{l}\text { Telephone problem solving } \\
\qquad 6 \text {; nurse) }\end{array}$ & Usual care \\
\hline Guided self-help & & & & & & \\
\hline $\begin{array}{l}\text { Joling } 2011 \\
\text { u (luhul) }\end{array}$ & 170 & Screening & $\begin{array}{l}\text { Subthreshold } \\
\text { depression }\end{array}$ & $\begin{array}{l}54 \\
81\end{array}$ & $\begin{array}{l}\text { Bibliotherapy } \\
\text { (3; nurse) }\end{array}$ & Usual care \\
\hline $\begin{array}{l}\text { Proudfoot } 2004 \\
\text { u (ulhuu) }\end{array}$ & 274 & Referral or screening & Depression & $\begin{array}{l}74 \\
44\end{array}$ & $\begin{array}{l}\text { Computerized (BT } \\
\text { ( } \leq 80 \mathrm{~min} ; \text { nurse })\end{array}$ & Usual care \\
\hline $\begin{array}{l}\text { Watkins } 2012 \\
\text { I (llull) }\end{array}$ & 82 & Screening & Depression & $\begin{array}{l}55 \\
46\end{array}$ & $\begin{array}{l}\text { Guided self-help } \\
\text { concreteness training } \\
\text { ( } \leq 4 \text {; psychologist })\end{array}$ & Usual care \\
\hline $\begin{array}{l}\text { Williams } 2013 \\
\text { u (ulhul) }\end{array}$ & 281 & Referral & Depression & $\begin{array}{l}68 \\
42\end{array}$ & $\begin{array}{l}\text { Guided self-help CBT } \\
\text { (3; psychologist) }\end{array}$ & Usual care \\
\hline Nolminimal con & & & & & & \\
\hline $\begin{array}{l}\text { de Graaf } 2009 \\
\text { I (llhll) }\end{array}$ & 303 & Screening & Depression & $\begin{array}{l}57 \\
45\end{array}$ & Computerized $\mathrm{CBT}^{\mathrm{d}}$ & Usual care \\
\hline $\begin{array}{l}\text { Levesque } 2011 \\
\quad \mathrm{~h} \text { (luhhl) }\end{array}$ & 350 & Screening & Depression & $\begin{array}{l}67 \\
47\end{array}$ & $\begin{array}{l}\text { Computer behavioral } \\
\text { intervention (TTM) }\end{array}$ & $\begin{array}{l}\text { Usual care, } \\
\text { no intervention }\end{array}$ \\
\hline $\begin{array}{l}\text { Levin } 2011 \\
\text { I (luhll) }\end{array}$ & 191 & Referral & Depression & $\begin{array}{l}77 \\
44\end{array}$ & Computer CBT & Usual care \\
\hline $\begin{array}{l}\text { Naylor } 2010 \\
\text { h (luhhl) }\end{array}$ & 38 & Screening & Depression & $\begin{array}{l}84 \\
51\end{array}$ & Bibliotherapy & Usual care \\
\hline
\end{tabular}

$\mathrm{BDI}=$ Beck Depression Inventory; BDI-FS = Beck Depression Inventory-Fast Screen; $\mathrm{c}=$ only change from baseline data available; $\mathrm{ca}=$ circa; $\mathrm{CBT}=\mathrm{cognitive} \mathrm{behavioral}$ therapy; CES-D = Center for Epidemiologic Studies-Depression Scale; CT = cognitive therapy; HAD-D = Hospital Anxiety and Depression Scale subscale depression;

HRSD = Hamilton Rating Scale for Depression; HSCL-D = Hopkins Symptom Checklist Depression Scale; $i=$ imputed data; MADRS = Montgomery Asberg Depression Rating

Scale; $\mathrm{nr}=$ not measured or reported; PHQ-9 = Patient Health Questionnaire for Depression; PT = psychotherapy; RDC = Research Diagnostic Criteria; SCID = Structured Clinical Interview for DSM Disorders; TTM = transtheoretical model.

Note: Risk of bias: $\mathrm{l}=$ low, $\mathrm{u}=$ unclear, $\mathrm{h}=$ high. First letter indicates the overall risk of blinding, not taking blinding into account; letters in parentheses sequentially indicate the risk of bias for the following 5 items: sequence generation, concealment, blinding, attrition, and selective reporting, respectively.

a Number of patients randomized (only in groups included in analyses).

b Comparator or control group not included in analyses. 


\begin{tabular}{|c|c|c|}
\hline $\begin{array}{l}\text { Further } \\
\text { Groups }\end{array}$ & $\begin{array}{c}\text { Week Posttreatment } \\
\text { Measurement } \\
\text { Score and Instrument }\end{array}$ & $\begin{array}{l}\text { Response } \\
\text { Remission }\end{array}$ \\
\hline \multirow{8}{*}{ Acupuncture $^{b}$} & 12 & BDI (i) \\
\hline & BDI & BDI (i) \\
\hline & Unclear & Improvement \\
\hline & $\mathrm{nr}$ & $\mathrm{nr}$ \\
\hline & 26 & BDI (i) \\
\hline & $\mathrm{BDI}$ & BDI (i) \\
\hline & 12 & PHQ-9 (i) \\
\hline & PHQ-9 & PHQ-9 (i) \\
\hline Usual care & 16 & HRSD (i) \\
\hline Amitriptyline ${ }^{b}$ & HRSD & HRSD \\
\hline \multirow[t]{16}{*}{ Usual care } & 16 & BDI (i) \\
\hline & & BDI (i) \\
\hline & 12 & HSCL-D \\
\hline & HSCL-D & $\mathrm{nr}$ \\
\hline & 16 & BDI (i) \\
\hline & $\mathrm{BDI}$ & BDI (i) \\
\hline & 26 & HSCL-D \\
\hline & HSCL-D & HSCL-D \\
\hline & 6 & $\mathrm{nr}$ \\
\hline & BDI (i) & BDI (i) \\
\hline & 6 & $\mathrm{nr}$ \\
\hline & BDI & BDI (i) \\
\hline & 12 & CES-D reduction $\geq 5$ \\
\hline & CES-D & CES-D $\leq 16$ \\
\hline & 9 & BDI (i) \\
\hline & $\mathrm{BDI}$ & BDI (i) \\
\hline \multirow{13}{*}{$\begin{array}{l}\text { Relaxation } \\
\text { control }^{b}\end{array}$} & 8 & HRSD (i) \\
\hline & $\mathrm{BDI}$ & HRSD (i) \\
\hline & 16 & $\mathrm{BDI}$ \\
\hline & $\mathrm{BDI}$ & BDI (i) \\
\hline & 8 & BDI reliable change \\
\hline & BDI & BDI (i) \\
\hline & 39 & $\mathrm{BDI} \leq 9+$ significant \\
\hline & BDI & change \\
\hline & & BDI (i) \\
\hline & 6 & SCID symptoms (i) \\
\hline & CES-D & $\mathrm{nr}$ \\
\hline & 6 & BDI-FS (i) \\
\hline & BDI-FS & BDI-FS (i) \\
\hline
\end{tabular}

c Trial included 2 separate groups (computerized CBT alone and in combination with usual care), which were pooled.

d Person providing the treatment was explicitly or probably a routine member of the primary care team. included a total of 32 groups receiving a psychological intervention. Twenty-seven trials had a usual care group for control, while 3 trials (with an additional group treated with pharmacotherapy) had a placebo control group. Furthermore, 6 trials with a usual care control group had additional comparator groups that were not included in our analyses ( 2 pharmacotherapy trials, 1 acupuncture, 1 talking control, 1 a psychoeducational depression recurrence prevention program, and 1 a relaxation control). The total number of patients randomized into the 62 treatment arms included in our analyses was 5,159 (median $=152$, range $=29-453)$.

The psychological intervention was face-to-face CBT in 7 treatment groups, face-to-face problemsolving therapy in 4 , face-to-face interpersonal psychotherapy in 2, other face-to-face psychological interventions in 6 ( 5 variable counseling interventions and 1 psychoeducational intervention), remote therapist-led CBT in 3, remote therapist-led problemsolving therapy in 2, guided self-help CBT in 4 , and no or minimal contact CBT in 4 treatment groups. There were no trials investigating psychodynamic therapy or face-to-face treatments in a group setting. Five of the 6 trials in patients with minor depression and/or dysthymia investigated face-to-face $(\mathrm{N}=3)$ or therapist-led $(\mathrm{N}=2)$ problem-solving therapy. In trials limited to patients with major depression, the psychological treatment was provided more frequently as a face-to-face intervention.

The overall risk of bias was considered low in 10, unclear in 9, and high in 11 trials (Table 1). The reporting of intervention details in usual care groups and of cointerventions (eg, percentage of patients receiving antidepressants) in the groups receiving psychological treatment was often insufficient, therefore, we were not able to classify this aspect in a reliable manner. From what was reported, however, it is obvious that the level of intervention or cointervention varied considerably.

\section{Efficacy/Effectiveness}

Compared with control groups, the effect (SMD) at completion of treatment was -0.30 (95\% CI, -0.48 to $-0.13)$ for face-to-face CBT, $-0.14(-0.40$ to 0.12$)$ for face-to-face problem-solving therapy, $-0.24(-0.47$ to $-0.02)$ for face-to-face interpersonal psychotherapy, $-0.28(-0.44$ to -0.12$)$ for other face-to-face psychological interventions, $-0.43(-0.62$ to -0.24$)$ for remote therapist-led CBT, $-0.56(-1.57$ to 0.45$)$ for remote therapist-led problem-solving therapy, -0.40 $(-0.69$ to -0.11$)$ for guided self-help CBT, and -0.27 $(-0.44$ to -0.10$)$ for no or minimal contact CBT (Figure 1). The differences between the effects of the different psychological interventions were not statistically significant $(P=.74)$. Findings were largely 
Figure 1. Standardized mean differences for posttreatment depression scores of psychological treatments compared with control (usual care or placebo).

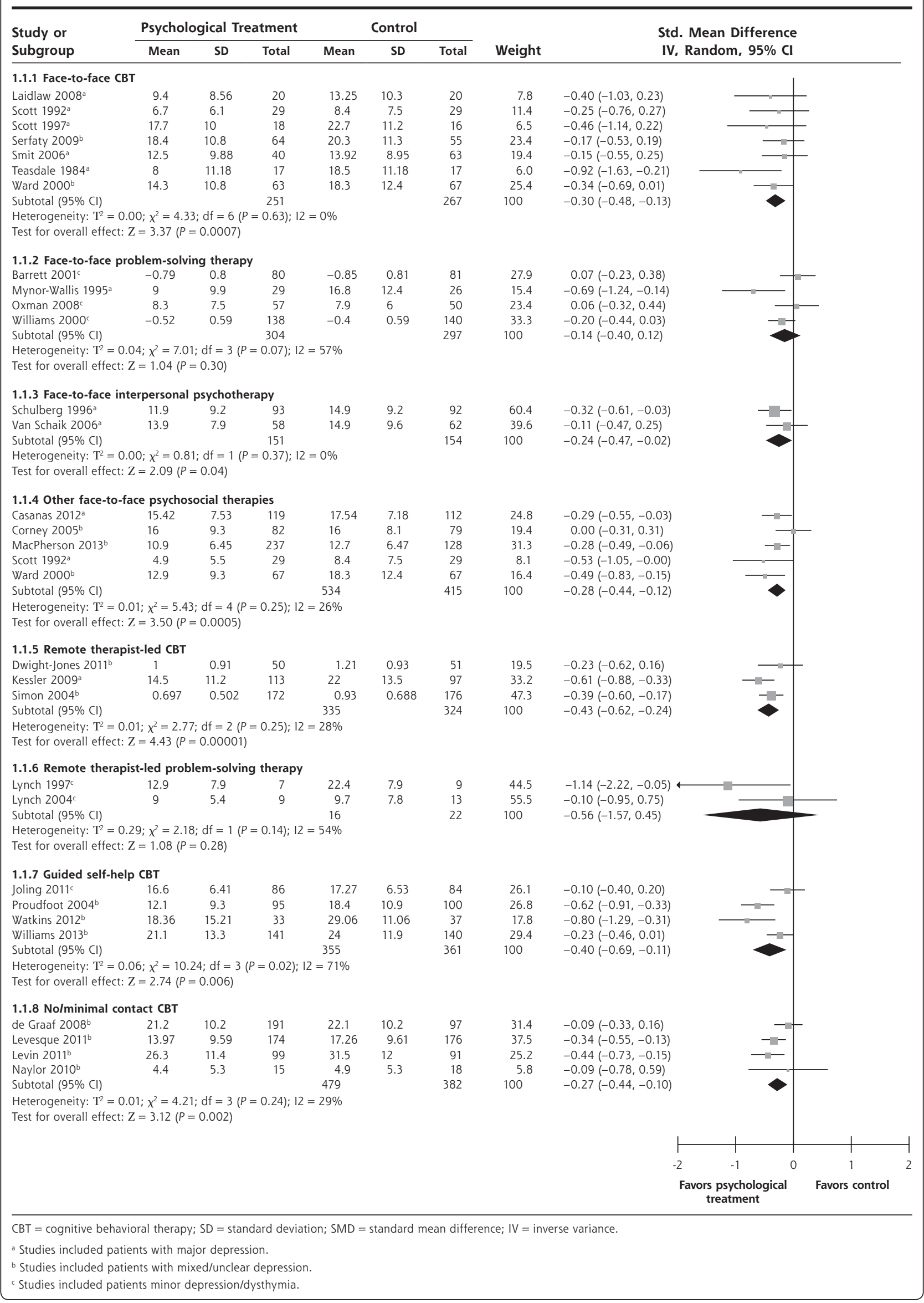


similar when response and remission (and the resulting numbers needed to treat) are used as outcomes instead of posttreatment depression scores (Table 2), but because of the lower proportion of patients achieving remission, 95\% confidence intervals are wide for this outcome, and differences compared with control are statistically significant only for 2 treatment modes (other face-to-face psychological interventions and guided self-help CBT).

On visual inspection the funnel plot for all studies

Table 2. Pooled Estimates for Response, Remission, and Study Discontinuation

\begin{tabular}{|c|c|c|c|c|c|}
\hline Therapy & Response & $\begin{array}{c}\mathrm{NNT}^{\mathrm{a}} \\
(95 \%-\mathrm{Cl})\end{array}$ & Remission & $\begin{array}{c}\mathrm{NNT}^{\mathrm{b}} \\
(95 \% \mathrm{Cl})\end{array}$ & Study Discontinuation \\
\hline Face-to-face CBT & & $10(5-47)$ & & na & \\
\hline OR $(95 \% \mathrm{Cl})$ & 1.58 (1.11 to 2.26$)$ & & 1.49 (0.90 to 2.46$)$ & & $0.98(0.52$ to 1.86$)$ \\
\hline $\mathrm{I}^{2}, \%$ & 0 & & 35 & & 25 \\
\hline No. of trials & 7 & & 7 & & 6 \\
\hline OR $(95 \% \mathrm{Cl})$ & $1.56(0.85$ to 2.86$)$ & & $1.29(0.83$ to 2.02$)$ & & $0.60(0.23$ to 1.57$)$ \\
\hline $1^{2}, \%$ & 55 & & 44 & & 80 \\
\hline No. of trials & 3 & & 4 & & 4 \\
\hline $\begin{array}{l}\text { Face-to-face interpersonal } \\
\text { psychotherapy }\end{array}$ & & na & & na & \\
\hline $\mathrm{I}^{2}, \%$ & 0 & & 12 & & na \\
\hline No. of trials & 2 & & 2 & & 1 \\
\hline $\begin{array}{l}\text { Other face-to-face psycho- } \\
\text { logical therapies }\end{array}$ & & $11(6-31)$ & & $10(5-35)$ & \\
\hline OR $(95 \% \mathrm{Cl})$ & 1.54 (1.17 to 2.03$)$ & & 1.68 (1.17 to 2.41$)$ & & $1.04(0.65$ to 1.67$)$ \\
\hline $\mathrm{I}^{2}, \%$ & 0 & & 0 & & 37 \\
\hline No. of trials & 6 & & 5 & & 5 \\
\hline Remote therapist-led CBT & & $6(4-13)$ & & na & \\
\hline OR $(95 \% \mathrm{Cl})$ & 2.04 (1.44 to 2.90$)$ & & 1.51 (0.98 to 2.32$)$ & & $1.05(0.29$ to 3.75$)$ \\
\hline $1^{2}, \%$ & 23 & & 36 & & 75 \\
\hline No. of trials & 3 & & 3 & & 2 \\
\hline $\begin{array}{l}\text { Remote therapist-led } \\
\text { problem-solving therapy }\end{array}$ & No data & No data & & na & \\
\hline OR $(95 \% \mathrm{Cl})$ & & & $1.22(0.23$ to 6.57$)$ & & $1.32(0.33$ to 5.26$)$ \\
\hline No. of trials & & & 2 & & 2 \\
\hline Guided self-help CBT & & $9(5-24)$ & & $9(5-28)$ & \\
\hline OR $(95 \% \mathrm{Cl})$ & $1.67(1.22$ to 2.28$)$ & & $1.73(1.21$ to 2.50$)$ & & 1.54 (1.00 to 2.37$)$ \\
\hline $\mathrm{I}^{2}, \%$ & 0 & & 0 & & 32 \\
\hline No. of trials & 4 & & 4 & & 4 \\
\hline No/minimal contact CBT & & $11(6-58)$ & & na & \\
\hline OR $(95 \% \mathrm{Cl})$ & 1.52 (1.09 to 2.13$)$ & & $1.46(0.96$ to 2.23$)$ & & $1.32(0.88$ to 2.00$)$ \\
\hline $\mathrm{I}^{2}, \%$ & 0 & & 0 & & 0 \\
\hline No. of trials & 4 & & 3 & & 4 \\
\hline \multicolumn{6}{|l|}{ Test for subgroup differences } \\
\hline$\chi^{2}$ & 3.32 & & 5.80 & & 4.44 \\
\hline$P$ value & .85 & & .67 & & .82 \\
\hline $1^{2}, \%$ & 0 & & 0 & & 0 \\
\hline All treatments & & $10(8-14)$ & & $15(10-25)$ & \\
\hline OR $(95 \% \mathrm{Cl})$ & $1.59(1.40$ to 1.80$)$ & & 1.42 (1.24 to 1.62$)$ & & $1.08(0.85$ to 1.38$)$ \\
\hline $\mathrm{I}^{2}, \%$ & 0 & & 0 & & 46 \\
\hline No. of trials & 27 & & 28 & & 27 \\
\hline
\end{tabular}

CBT = cognitive behavioral therapy; $I^{2}=$ measure of statistical heterogeneity; na = not applicable; NNT = number needed to treat; OR = odds ratio.

Note: NNTs for study discontinuation cannot be calculated in a valid manner as the confidence intervals of all odds ratios include the value 1 .

a Proportion of control group patients with response $=27 \%$.

b Proportion of control group patients with remission $=23 \%$. 


\section{Figure 2. Funnel plot plotting study precision against size of the treatment effect.}

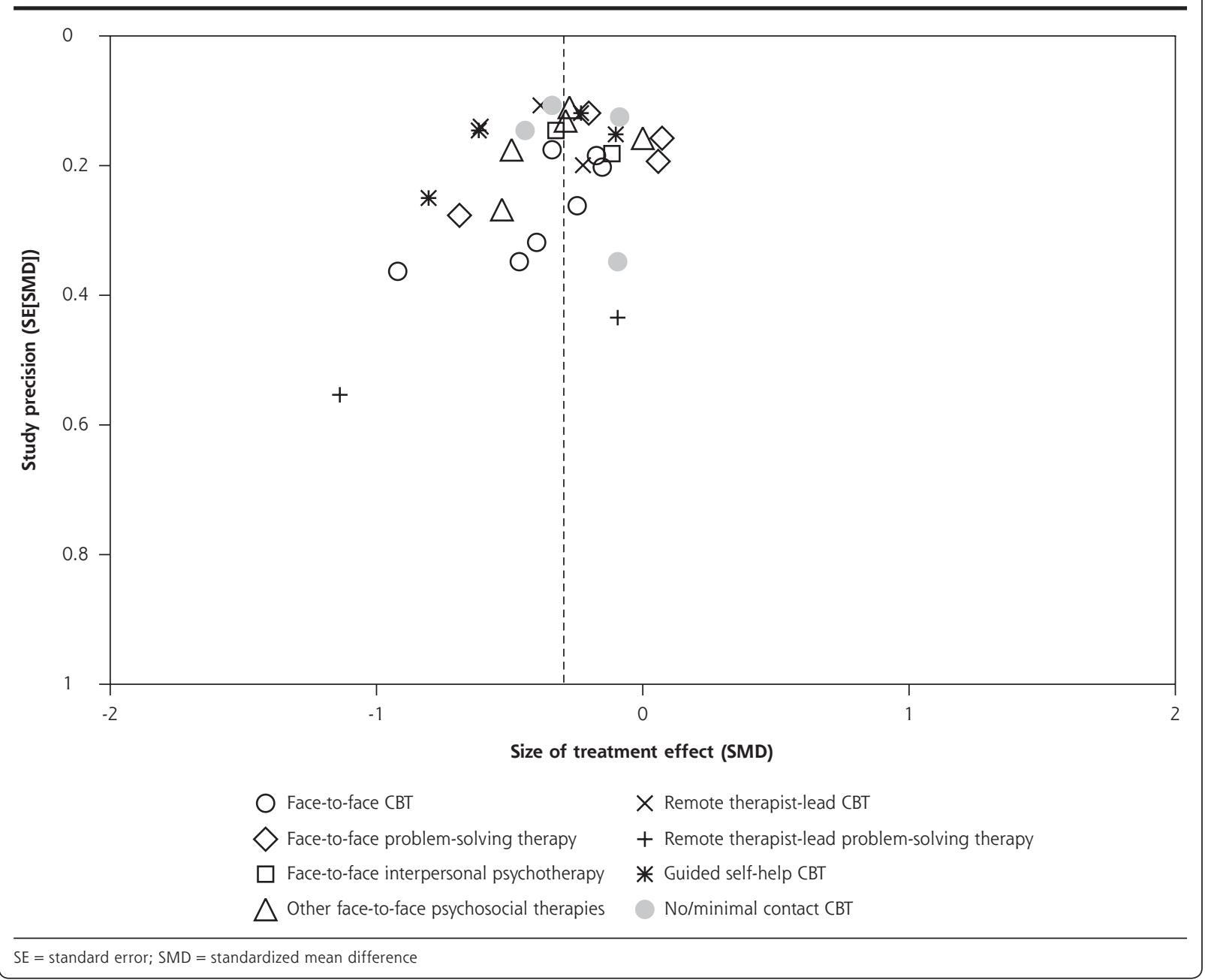

plotting treatment effects against their precision seems asymmetrical (Figure 2). When funnel plots were produced for each group of treatments separately, inspection suggested asymmetry only for face-to-face CBT. None of the treatment groups, however, included more than 7 trials. As a result, asymmetry tests were not performed.

Subgroup analyses (Table 3) suggest that psychological treatments might possibly be less effective in patients having minor depression and/or dysthymia (pooled SMD was -0.09) compared with patients with major depression (pooled SMD, -0.38 ) or with a variety of depressive disorders or those not further specified (pooled SMD, -0.31). There was a trend for smaller effect sizes in trials limited to elderly patients (SMD, -0.17 vs -0.31 in trials not limited to elderly patients). There were no clear differences in outcomes in subgroup analyses according to recruitment approach, delivery mode, treatment concept, number of treatment sessions, risk of bias, and sample size.
When pooling results from all available psychological treatments, the SMD for posttreatment scores was $-0.29(-0.37$ to -0.22$)$ with a moderate statistical heterogeneity of the results $\left(\mathrm{I}^{2}=34 \%, \chi^{2}\right.$ test for heterogeneity, $P=.04)$. For response $\mathrm{OR}=1.59(1.40$ to $\left.1.80_{i} \mathrm{I}^{2}=0 \%\right)$ and for remission, $\mathrm{OR}=1.42(1.24$ to $\left.1.62 ; \mathrm{I}^{2}=0 \%\right)$. The number need to treat to achieve 1 response was 10 ( 8 to 14 ) and to achieve 1 remission was 15 (10 to 25$)$.

\section{Acceptability}

The included trials reported attrition in a highly variable manner. Some reported only the number of patients with missing outcome data, some the number of patients dropping out of the study, and some the number of patients discontinuing treatment (but providing outcome data). When pooling these heterogeneous data, study discontinuation did not differ significantly between groups receiving a psychological treatment and control groups (Table 2). 


\section{DISCUSSION}

A variety of psychological treatments have been investigated in randomized trials in depressed primary care patients. CBT approaches have been tested most often.
Overall, there is evidence that psychological treatments are superior to usual care alone, the size of the effects being small to moderate. Our analyses suggest that the differences between different types of psychological treatments are minor, and remote therapist-led, guided self-help, and minimalcontact approaches can yield effects similar to personalized face-to-face therapies. There are also hints that psychological therapies might be less effective for patients having minor depression and dysthymia than for patients with major depression.

\section{Strengths and Limitations}

Compared with available systematic reviews of primary care trials, ${ }^{14-16}$ our analysis included a much larger number of trials, which allowed us to build subgroups of treatments with broadly similar interventions and delivery modes. The findings were highly consistent across the 3 analyzed effectiveness outcomes. Yet important limitations must be taken into account when interpreting our findings. The number of trials and the number of patients per treatment group are small. For at least one of these groups (remote therapist-led CBT), the numbers are so small that the respective results are accompanied by large uncertainty. Even within treatment groups intervention details sometimes differed to a considerable extent. The conditions under treatment varied across studies (major depression, minor depression, dysthymia) and were diagnosed by different criteria. In one-half the studies, participants were recruited by screening primary care patients; in the other onehalf, depressed patients were referred by their primary care physicians. Some included trials have to be considered

CBT = cognitive behavioral therapy; na = not applicable; PST = problem-solving therapy; SMD = standardized mean difference. 
pragmatic effectiveness trials with broad inclusion criteria and allowing for variability between therapists, whereas others are explanatory efficacy studies trying to provide a proof of principle for a clearly defined manual-based treatment procedure. The psychological intervention was provided by a trained member of the routine primary care team in 4 trials only.

The intensity of treatment in usual care groups and the level of usual care interventions in groups receiving psychological treatments varied, which can have a major impact on the effect estimates. Only one-third of the trials were considered to have a low risk of bias, and publication bias seems at least possible. The reporting of treatment discontinuation, dropout from the study, and loss to follow-up rarely provided sufficient detail to assess whether attrition was due to acceptability of the treatment or organizational problems. No study reported adverse events or adverse effects for psychological treatments (not even studies including a pharmacotherapy treatment group). As a result, we could not assess acceptability and feasibility of treatments to the extent planned in our protocol. ${ }^{17}$ In summary, given the limited number, rather low quality, and considerable heterogeneity of the available studies, the findings of our review have to be interpreted carefully.

\section{Comparison With Other Studies}

The pooled estimate of all 29 studies providing posttreatment depression score data in our review ( $\mathrm{SMD}=-0.29)$ is similar to the pooled estimate found in a meta-analysis from 2009 that included 15 trials $(\mathrm{SMD}=-0.31) .{ }^{15}$ This effect of treatment compared with usual care or placebo must be considered as relatively small according to usual standards. ${ }^{22,26}$ Nevertheless, usual care should not be equated to no treatment or a wait list control. A recent network meta-analysis by Barth et al of 198 trials not limited to primary care patients showed that compared with a wait list control, both usual care and placebo interventions were associated, with a SMD of -0.33 , and the SMD of psychological treatments compared with wait list controls was -0.62 , which would be considered to be a moderate or large effect. ${ }^{8}$ The amount and robustness of evidence for individual treatment approaches varied, which is similar to our findings, but there was little evidence that treatment effects differed. Barth et al also found that larger trials yielded less optimistic findings than smaller trials. Another meta-analytic study of a similar data set concluded that the effects of psychological treatments for adult depression are likely overestimated because of publication bias. ${ }^{27}$ The funnel plot in our review looks asymmetrical, but pooled estimates in larger and smaller studies included in our review dif- fered only marginally. Even so, we cannot rule out that the effects of psychological treatments in our metaanalysis are to some extent overestimated.

We could not confirm the finding of the metaanalysis by Cuijpers et al that effects of psychological treatments are smaller in trials in which participants are recruited by screening ${ }_{1}^{15}$ but we did find that the effects were smaller in trials in patients with minor depression or dysthymia. Other studies point to a similar direction. ${ }^{28,29}$ Still, mixing acute and persistent forms of minor depression may have masked important clinical variation, as responsiveness to psychotherapeutic treatments is likely to vary according to the persistence of symptoms. ${ }^{18}$ When interpreting our findings, it must be kept in mind that 5 of the 6 trials focusing on dysthymia or minor depression in our meta-analysis investigated problem-solving therapy. In our subgroup analyses we also found a trend that psychological treatments were slightly less effective in the elderly, but this finding might be by chance, and an earlier, large meta-analysis by Cuijpers et al not restricted to primary care did not find a significant difference in effects between younger and older adults. ${ }^{30}$

\section{Interpretation}

The population-wide implementation of psychological treatments into primary care, when compared with pharmacotherapy, is associated with considerably larger challenges. Before effective psychological care can be delivered, a sufficient number of qualified clinicians must be integrated into primary care on a countrywide level. It is of major interest, therefore, that remote, reduced, or minimal-contact CBT-based interventions and intense, face-to-face treatments seem to be similarly effective. This finding should be interpreted carefully, however, given the limited number and moderate size of the identified studies. Other major metaanalyses did not investigate the influence of different delivery modalities as we did. They also, surprisingly, did not find an influence of treatment dose..$^{8,15}$

We hypothesize 2 possible explanations. First, more-intense treatment might indeed not be superior to less-intense treatment. There is some evidence from naturalistic studies indicating that the relationship between treatment dose and response is highly vari$a_{b l e} e^{31}$ and that a relevant proportion of patients already improves significantly after few sessions. ${ }^{32}$ Another study, however, found that response rates were low in patient samples receiving only a few sessions. ${ }^{33}$ Second, trials testing a certain treatment delivery mode might be more likely to recruit participants who are motivated to use that delivery mode specifically. For example, patients preferring face-to-face psychotherapy might be less likely to embark on and comply with a 
no/minimal-contact treatment (and vice versa). Furthermore, clinical characteristics are also likely to be associated with the mode of treatment delivery. For example, in our trial set, studies limited to patients with major depressive disorders were more likely to investigate a face-to-face intervention. Thus, our findings might indicate less that all treatment delivery modes are similarly effective but rather that they can be similarly effective when applied in motivated and indicated target groups. For successful implementation of psychological treatments in primary health care, it might be desirable that several different options (eg, face-to-face, guided self-help, and minimal contact) are available.

\section{Implications for Practice}

Our findings confirm that psychological treatments are effective in depressed primary care patients. This finding is reassuring for both patients and clinicians wishing to pursue nonpharmacological options. The lack of major differences between different types of psychological therapies suggests that an eclectic rather than a dogmatic approach should be favored. At least for CBT approaches, interventions that are less resource intensive seem to yield effects similar to interventions that are more intensive. Depending on what is available in a practice, center, or region, primary care physicians are encouraged to consider referring patients with depression to psychological therapy.

\section{Future Research}

Large pragmatic trials comparing long-term outcomes and acceptability of different psychological treatment strategies in depressed primary care patients are urgently needed. The available evidence for nonpharmacological treatment, although promising, is insufficient to guide routine primary care practice and health policy. Given the equivocal results in patients with minor depression or dysthymia and the widespread use of psychological treatments in these conditions, future studies seem of particular relevance.

Tested interventions should be able to be implemented in routine primary care, and trials should carefully follow existing reporting guidelines to facilitate future meta-analyses. ${ }^{34-36}$ The documentation of adherence, discontinuation, and adverse events should be improved in future research on psychological treatments for depression. Observational studies can investigate the long-term effects of psychological interventions that are implemented on a populationwide level. Future randomized trials and observational studies should carefully document the recruitment processes and why potentially eligible patients were not included or chose a given modality. More complex designs, such as a double-randomized preference trial, could investigate the effects of treatment preference and selection. ${ }^{37,38}$

To read or post commentaries in response to this article, see it online at http://www.annfammed.org/content/13/1/56.

Key words: depression; depressive disorders; psychotherapy; cognitive therapy; therapeutics; primary health care; review, systematic

Submitted July 24, 2014; submitted, revised, September 12, 2014; accepted September 17, 2014.

Funding support: The study was funded by the German Ministry of Education and Research (grant 01KG1012).

Disclaimer: The sponsor was not involved in the design, data collection, analysis, interpretation, writing of the report or decision to submit the report for publication.

Acknowledgments: We would like to thank all authors of included studies who provided additional information on request.

Systematic review registration: 01KG1012 at http://www.gesundheitsforschung-bmbf.de/de/2852.php.

Supplementary materials: Available at http://www.AnnFamMed. org/content/13/1/56/suppl/DC1/.

\section{REFERENCES}

1. Demyttenaere K, Bruffaerts R, Posada-Villa J, et al; WHO World Mental Health Survey Consortium. Prevalence, severity, and unmet need for treatment of mental disorders in the World Health Organization World Mental Health Surveys. JAMA. 2004;291(21):2581-2590.

2. Mathers CD, Loncar D. Projections of global mortality and burden of disease from 2002 to 2030. PLoS Med. 2006;3(11):e442.

3. Parikh SV, Segal ZV, Grigoriadis S, et al; Canadian Network for Mood and Anxiety Treatments (CANMAT). Canadian Network for Mood and Anxiety Treatments (CANMAT) clinical guidelines for the management of major depressive disorder in adults. II. Psychotherapy alone or in combination with antidepressant medication. J Affect Disord. 2009;117(Suppl 1):S15-S25.

4. National Collaborating Centre for Mental Health. Depression: The NICE Guideline on the Treatment and Management of Depression in Adults, updated edition. Leicester, England: British Psychological Society; London, England: Royal College of Psychiatrists; 2010.

5. DGPPN. BÄK, KBV, AWMF, AkdÄ, PPtK, DAGSHG, DEGAM, DGPM, DGPS, DGRW. S3-Leitlinie/Nationale Versorgungleitlinie Unipolare Depression - Langfassung. http://www.leitlinien.de/nvl/depression/. Published 2009.

6. Mitchell J, Trangle M, Degnan B, et al Adult Depression in Primary Care. Bloomington, MN: Institute for Clinical Systems Improvement; 2012. https://www.icsi.org/_asset/fnhdm3/Depr-Interactive0512b. pdf. Updated September 2013.

7. Cuijpers P, Andersson G, Donker T, van Straten A. Psychological treatment of depression: results of a series of meta-analyses. Nord J Psychiatry. 2011;65(6):354-364.

8. Barth J, Munder T, Gerger H, et al. Comparative efficacy of seven psychotherapeutic interventions for patients with depression: a network meta-analysis. PLoS Med. 2013;10(5):e1001454.

9. Simon GE, VonKorff M. Recognition, management, and outcomes of depression in primary care. Arch Fam Med. 1995;4(2):99-105.

10. Schwenk TL, Coyne JC, Fechner-Bates S. Differences between detected and undetected patients in primary care and depressed psychiatric patients. Gen Hosp Psychiatry. 1996;18(6):407-415. 
11. Alonso J, Angermeyer MC, Bernert S, et al; ESEMeD/MHEDEA 2000 Investigators, European Study of the Epidemiology of Mental Disorders (ESEMeD) Project. Disability and quality of life impact of mental disorders in Europe: results from the European Study of the Epidemiology of Mental Disorders (ESEMeD) project. Acta Psychiatr Scand Suppl. 2004;420(420):38-46.

12. Williamson PS, Yates WR. The initial presentation of depression in family practice and psychiatric outpatients. Gen Hosp Psychiatry. 1989;11(3):188-193, discussion 216-221.

13. Kroenke K, Price RK. Symptoms in the community. Prevalence, classification, and psychiatric comorbidity. Arch Intern Med. 1993; 153(21):2474-2480.

14. Bortolotti B, Menchetti M, Bellini F, Montaguti MB, Berardi D. Psychological interventions for major depression in primary care: a meta-analytic review of randomized controlled trials. Gen Hosp Psychiatry. 2008;30(4):293-302.

15. Cuijpers P, van Straten A, van Schaik A, Andersson G. Psychological treatment of depression in primary care: a meta-analysis. $\mathrm{Br} J \mathrm{Gen}$ Pract. 2009;59(559):e51-e60.

16. Høifødt RS, Strøm C, Kolstrup N, Eisemann M, Waterloo K. Effectiveness of cognitive behavioural therapy in primary health care: a review. Fam Pract. 2011;28(5):489-504.

17. Linde K, Schumann I, Meissner K, et al. Treatment of depressive disorders in primary care-protocol of a multiple treatment systematic review of randomized controlled trials. BMC Fam Pract. 2011;12:127.

18. Kriston L, von Wolff A, Westphal A, Hölzel LP, Härter M. Efficacy and acceptability of acute treatments for persistent depressive disorder: a network meta-analysis. Depress Anxiety. 2014;31(8):621-630. 10.1002/da.22236.

19. Linde K, Kriston L, Rücker G, et al. Effcacy and acceptability of pharmacological treatments for depressive disorders in primary care: systematic review and network meta-analysis. Ann Fam Med. 2014;12(6):69-79.

20. Cape J, Whittington C, Buszewicz M, Wallace P, Underwood L. Brief psychological therapies for anxiety and depression in primary care: meta-analysis and meta-regression. BMC Med. 2010;8:38.

21. Huntley AL, Araya R, Salisbury C. Group psychological therapies for depression in the community: systematic review and meta-analysis. BrJ Psychiatry. 2012;200(3):184-190.

22. Higgins JPT, Green S, eds. Cochrane Handbook for Systematic Reviews of Interventions. Version 5.1.0. Updated March 2011. http://handbook.cochrane.org/.

23. Furukawa TA, Cipriani A, Barbui C, Brambilla P, Watanabe N. Imputing response rates from means and standard deviations in meta-analyses. Int Clin Psychopharmacol. 2005;20(1):49-52.

24. Craig P, Dieppe P, Macintyre S, Michie S, Nazareth I, Petticrew M. Developing and evaluating complex interventions: the new Medical Research Council guidance. BMJ. 2008;337:a1655.
25. Kriston L. Dealing with clinical heterogeneity in meta-analysis. Assumptions, methods, interpretation. Int J Methods Psychiatr Res. 2013;22(1):1-15.

26. Cohen J. Statistical Power Analysis for the Behavioral Sciences. Hillsdale, NJ: Lawrence Erlbaum Associates; 1986.

27. Cuijpers P, Smit F, Bohlmeijer E, Hollon SD, Andersson G. Efficacy of cognitive-behavioural therapy and other psychological treatments for adult depression: meta-analytic study of publication bias. Br J Psychiatry. 2010;196(3):173-178.

28. Driessen E, Cuijpers P, Hollon SD, Dekker JJ. Does pretreatment severity moderate the efficacy of psychological treatment of adult outpatient depression? A meta-analysis. J Consult Clin Psychol. 2010;78(5):668-680.

29. Imel ZE, Malterer MB, McKay KM, Wampold BE. A meta-analysis of psychotherapy and medication in unipolar depression and dysthymia. J Affect Disord. 2008;110(3):197-206.

30. Cuijpers $P$, van Straten A, Smit F, Andersson G. Is psychotherapy for depression equally effective in younger and older adults? A metaregression analysis. Int Psychogeriatr. 2009;21(1):16-24.

31. Baldwin SA, Berkeljon A, Atkins DC, Olsen JA, Nielsen SL. Rates of change in naturalistic psychotherapy: contrasting dose-effect and good-enough level models of change. J Consult Clin Psychol. 2009;77(2):203-211.

32. Stulz N, Lutz W, Kopta SM, Minami T, Saunders SM. Dose-effect relationship in routine outpatient psychotherapy: does treatment duration matter? J Couns Psychol. 2013;60(4):593-600.

33. Hansen NB, Lambert MJ, Forman EM. The psychotherapy doseresponse effect and its implications for treatment delivery services. Clin Psychol Sci Pract. 2002;9(3):329-343.

34. Schulz KF, Altman DG, Moher D; CONSORT Group. CONSORT 2010 Statement: updated guidelines for reporting parallel group randomised trials. BMC Med. 2010;8:18.

35. Zwarenstein M, Treweek S, Gagnier JJ, et al; CONSORT group; Pragmatic Trials in Healthcare (Practihc) group. Improving the reporting of pragmatic trials: an extension of the CONSORT statement. BMJ. 2008;337:a2390.

36. Boutron I, Moher D, Altman DG, Schulz KF, Ravaud P; CONSORT Group. Extending the CONSORT statement to randomized trials of nonpharmacologic treatment: explanation and elaboration. Ann Intern Med. 2008;148(4):295-309.

37. Rücker $\mathrm{G}$. A two-stage trial design for testing treatment, self-selection and treatment preference effects. Stat Med. 1989;8(4):477-485.

38. Marcus SM, Stuart EA, Wang P, Shadish WR, Steiner PM. Estimating the causal effect of randomization versus treatment preference in a doubly randomized preference trial. Psychol Methods. 2012; 17(2):244-254. 